\title{
Walkability in upper east Texas cities and implications for physical activity and health
}

\author{
Wycliffe W. Njororai Simiyu ${ }^{1}$ \\ Fletcher J. Njororai ${ }^{2}$ \\ Billystrom Aronya Jivetti ${ }^{3}$
}

\begin{abstract}
Introduction: Physical activity is an important intervention strategy against the increasing cases of overweight and obesity in the USA and many other parts of the world. Walking has been identified as a component of physical activity that can easily be incorporated into one's lifestyle. Recent studies on physical activity have focused on promoting walking as a health enhancing endeavor.

Purpose: This study examined the walkability of the environments in 57 cities drawn from 22 different counties in upper east Texas within the USA.

Methods and materials: The data for all the 57 key cities in upper east Texas were collected from the Walkscore.com.

Results: It was established that $13(22.8 \%)$ of the cities had walkable scores below $24 \%$; $26(45.6 \%)$ had between 25 and 49; 13 (22.8\%) between 51 and 69; 4 (7\%) had between 70 and 89, and only one city had a score of 91 .

Discussion: The vast majority of cities $(39,68.42 \%)$ had walkable scores that show a high dependability on vehicle transport; with only $5(8.8 \%)$ cities being rated as very walkable or a walker's paradise. This reflects a high dependence on vehicles in the upper east Texas region and therefore minimal walking.

Recommendations: There is need to actively pursue an agenda that promotes infrastructural investments that can bring about ease of walking and accessibility of community services at close range. Stakeholders need to collectively come together to generate interventions that can enhance the well-being of the residents in of upper east Texas.
\end{abstract}

Keywords: Physical activity; Walking; Walkability score; Social capital; Built environment

\section{Introduction}

Physical activity (PA) is a health enhancing behavior that requires to be engaged in at regular intervals. For physical activity benefits to accrue, one needs to be only active for at least 150 minutes a week for adults and 60 minutes a day for school-age youth. This physical activity

\footnotetext{
1 Associate Professor, University of Texas at Tyler, Department of Health and Kinesiology, Texas, USA, wnjororai@uttyler.edu

2 Assistant Professor, University of Texas at Tyler, Department of Health and Kinesiology, Texas, USA, fnjororai@uttyler.edu

${ }^{3}$ STEM Coordinator, Texas College, Department of Academic Affairs, Tyler, Texas, kingbillyke@yahoo.com
} 
Njororai Simiyu, W. W., Njororai, F. J., \& Jivetti, B. A (2016). Walkability in upper east Texas cities and implications for physical activity and health. International Journal of Human Sciences, 13(1), 487-499. doi:10.14687/ijhs.v13i1.3438

can even occur in short bouts, lasting at least 10 minutes (Collins \& Fulton, 2015). Unfortunately, only one-half of adults (Blackwell, Lucas and Clarke, 2014) and about one quarter of high school students (Kann et al., 2014) are sufficiently active to realize the health benefits of physical activity. To improve population levels of physical activity, an increase in walking may be an important place to start. Indeed people who live long and fulfilling lives suggest that physical activity should be incorporated in the natural cycle of life so that it is a lifestyle and not a separate activity.

One of the components of physical activity that is easy and natural to incorporate into one's lifestyle is walking. Recent researches on physical activity advocate for increased focus and promotion of walking as a health enhancing endeavor (Collins and Fulton, 2015; Kegler et al., 2015). According to these authors, many Americans walk regularly especially for shopping, transportation and exercise. The Center for Disease Control (CDC, 2012) documented that 62\% of USA adults reported walking for leisure or transport in the past week, while Watson et al., (2015) report that $54 \%$ of women and $41 \%$ of men in the USA cite walking as their most common activity during the past month. Similarly, Song et al. (2012) report that walking was the most frequently reported physical activity among high school students in the USA. However, according to Ferreira et al., (2006), despite the many health benefits of engaging in physical activity, many young people are not engaging in recommended levels of PA Johnson, 2000; WHO, 2000a, b, 2004). According to Johnson (2000) and WHO (2000a, b, 2004), longitudinal studies have shown that a steep decrease in PA levels occurs during adolescence and that PA levels established in youth tend to track into adulthood. These trends show that physical activity promotion in childhood and youth can facilitate a carryover of healthful habits into adulthood and a lifelong protection from other risk factors. This implies the need to promote physical activity among all age groups at community and neighborhood levels. There is, therefore, a need to prioritize having physical activity-friendly environments in current public health policies (WHO, 1998, 2004).

Given the relationship between physical inactivity and obesity prevalence in the USA, a focus on the accessibility and opportunities for physical activity engagement is an issue worth exploring as recent studies have indeed demonstrated associations between childhood obesity and environmental features, namely at the home and neighborhood level (Ferreira et al., 2006). According to these authors, it is important to study and alter environments that promote or hinder obesity-inducing habits such as low physical activity. Environmental influences are critical as they either facilitate or hinder access to physical activity at all age levels. This study, therefore, endeavored to examine the walkability of the environments in cities drawn from the upper east Texas region in the USA.

Ogden et al., (2015) reported that $36.5 \%$ of adults in the USA were obese during the 2011 to 2014 period. However, overall the report shows that prevalence of obesity among middle -aged adults aged 40-59 (40.2\%) and older adults aged 60 and over $(37.0 \%)$ was higher than among younger adults aged 20-39 (32.3\%). Despite the differences, no significant difference in prevalence was observed between middle-aged and older adults (Ogden et al., 2015). The report continues to point out that the prevalence of obesity among women $(38.3 \%)$ was higher than among men (34.3\%). For adults aged 20-39 and 40-59, the prevalence of obesity was higher among women than among men, but the difference between older women and men aged 60 and over was not significant. For the young people aged between 2 and 19 years, the prevalence of obesity was $17.0 \%$ in 2011-2014. Overall, the prevalence of obesity among preschool-aged children (2-5 years) (8.9\%) was lower than among school-aged children (6-11 years) $(17.5 \%)$ and adolescents (12-19 years) (20.5\%). The same pattern was seen in both males and females. One significant observation was that "trends in obesity prevalence show no increase among youth since 2003-2004, but trends do show increases in both adults and youth from 1999-2000 
Njororai Simiyu, W. W., Njororai, F. J., \& Jivetti, B. A (2016). Walkability in upper east Texas cities and implications for physical activity and health. International Journal of Human Sciences, 13(1), 487-499. doi:10.14687/ijhs.v13i1.3438

through 2013-2014" (p. 6). This is a disturbing observation given the many initiatives and programs to combat obesity in the USA.

The prevalence of obesity and overweight cases is, therefore, a serious health issue facing all age groups and gender. The age factor is critical especially for the intervention measures that can help address the physical activity needs of different segments of society. The upper east Texas region's (see Table 1) population is older on average in comparison to state and the national averages. In $2007,33.5$ percent of the region's population was under the age of $25 ; 51.5$ percent were aged 25 to 64; and 15 percent were 65 or older. The 65 and older age group accounted for 15 percent of the region's population, considerably more than the state's 10 percent share. In U.S. as a whole, 12.5 percent were aged 65 or older in 2007(Combs, 2008). The aging population and the prevalence of cardiovascular related health issues, as well as higher numbers of the uninsured residents (Combs, 2008), call for realistic and practical intervention measures.

Research shows that some of the benefits of engaging in regular physical activity include reduced risk of chronic disease and leading of a healthier, longer life (Ogden et al., 2012). Cardiovascular benefits of regular physical activity include lower risk for heart disease, high blood pressure, stroke, abnormal blood cholesterol and triglycerides, diabetes, and obesity. Despite these findings, many Texans, like most Americans, are sedentary (Njororai, Njororai \& Jivetti, 2015). In 2012, the proportion of Texas adults who reported no participation in any physical activity in the previous month was $27.3 \%$, while $65.9 \%$ of the adults were in the overweight and obese categories. Among the adolescents, only $27.2 \%$ were physically active for a total of at least 60 minutes per day on each of the 7 days prior to the survey. Additionally, only $37.4 \%$ of the adolescents attended daily physical education classes in an average week in school (Valls, 2012).

To date, a variety of interventions that have shown success in promoting physical activity and fitness, including: limiting screen time for youth, establishing policies for physical activity in child care and school settings; creating physical activity curricula based on national standards; establishing worksite wellness programs that promote physical activity by offering incentives, designated exercise areas, safe walking paths and stairwell programs; supporting health care provider reminders related to physical activity screening and education; building infrastructure for safe walking and biking in the community; and improving access to public transportation (Njororai, et al., 2015). Sinnett et al., (2011) assert that the places we live shape our lives. According to Sinnett et al., (2011), citizens of any great city, town and village feel that what makes their locality great are issues that affect the walking environment including: safety when walking around their area; the attractiveness of their local streets; the quality and proximity of their local shops and services; and the care taken to maintain the basic quality of the street. The realization that physical activity is no longer the province of school based physical education, but a community affair has prompted various federal, state and local agencies to take initiatives to enhance the promotion and participation in physical activity at the local community level (Njororai, et al., 2015). Therefore, there is a huge desire on the part of various federal and state agencies to raise the proportion of adults, children, and youth who engage in regular physical activity (Njororai, et al., 2015).

The commitment to raise the level of participation in physical activity at the community level should be evident in the localities where people reside. Critical to the success of any initiatives include people having access to school playgrounds, recreation, and sports-related parks and facilities, street designs that provide for bicycling, walking to and from shopping stores, fresh food markets, and other amenities that can easily be accessed on foot or on a bicycle rather than by car (Njororai, et al., 2015). Availability and ease of access to such amenities would give an indicator of the suitability of the area for physical activity engagement. One of the ways that a 
Njororai Simiyu, W. W., Njororai, F. J., \& Jivetti, B. A (2016). Walkability in upper east Texas cities and implications for physical activity and health. International Journal of Human Sciences, 13(1), 487-499. doi:10.14687/ijhs.v13i1.3438

locality or city can be evaluated on their walkability is by using the walk score (Njororai, et al., 2015). Indeed walkability has been linked to quality of life in many ways. According to Rogers et al., (2010) health related benefits of physical exercise, the accessibility and access benefits of being able to walk to obtain some of your daily needs, or the mental health and social benefits of reduced isolation are a few of the many positive impacts on quality of life that can result from a walkable neighborhood. This is even more so in the modern society where in the face of increasing energy costs and climate considerations, the ability to walk to important locations is a key component of sustainable communities (Rogers et al., 2010).

Research has suggested that individuals learn to trust one another in communities where they get opportunities to meet and interact (Kegler, et al., 2015; Lund, 2003). Social connections and networks can increase the resiliency of a neighborhood in a myriad of ways including providing emotional support or sharing resources when a need arises. Daily life can be enriched (Putnam, 2000) and resilience may be increased to face the different social, economic, and environmental challenges (Adger, 2003). Leyden (2003) suggests that the way in which communities and neighborhoods are designed and built affects social capital and thus physical and mental health. Indeed, the study's findings indicate that residents living in walkable, mixeduse neighborhoods are more likely to know their neighbors, engage in political participation, trust others, and be involved socially.

Quality of life indicators and measurements of community sustainability are closely related and mutually relevant (Sirgy et al., 2006). Examining indicators of urban quality of life, whether they are objective or subjective, is a topic of interest in the quality of life literature (McCrea et al., 2006). Walkability and the importance of third places, that are not home nor work, have been linked to components of social capital and quality of life (Frank et al., 2009). Economic well-being is often associated with quality of life indicators as communities with higher levels of social capital have been found to exhibit better economic performance standards (Putnam, 2000).

Halstead and Deller (1997) examined how community infrastructure impacts economic development in communities and found that it was quality of life that influenced individual companies' location preferences more than physical infrastructure such as roads and bridges. Quality of life and social capital are often discussed in similar circles but the two are rarely examined together. The land use design and physical infrastructure of neighborhoods and regions provide the conduits for individuals to meet each other, theoretically increasing social capital (Jarema et al., 2009). A neighborhood that provides residents with easy access to municipal infrastructure such as post offices, town parks, playgrounds, coffee shops, restaurants, barbershops and club meeting venues will theoretically have high values of social capital. One can argue that communities are more resilient if they have the capacity to utilize social capital and access to physical infrastructure that supports the interaction of residents. In rural settings, Kegler et al., (2015) identified destination such as homes, stores, churches, barns and feeder roads as major points of social contacts. Other key features of rural communities that are constraints to physical activity involvement include presence of sidewalks, shade, safety, and traffic flow, presence of dogs and insects, and aesthetics. The common physical activities seen in rural neighborhoods included walking, yard work, biking, playing ball, gardening, fishing, and jogging (Kegler et al., 2015). However, irrespective of whether a community is in the urban or rural area, the human connection is a vital one. Thus, social capital has the potential to be utilized in a manner that increases the quality of life in a community or region, thereby narrowing the gap between what is expected and experienced. Thus it is vital that planning agencies recognize the walkability needs in the various cities and neighborhoods so that intervention measures can be 
Njororai Simiyu, W. W., Njororai, F. J., \& Jivetti, B. A (2016). Walkability in upper east Texas cities and implications for physical activity and health. International Journal of Human Sciences, 13(1), 487-499. doi:10.14687/ijhs.v13i1.3438

generated to enhance the infrastructure and the eventual wellbeing of the residents. These can be accomplished by using information from walk scores.

\section{Purpose of the study}

Walk score is a viable tool that provides information about the walkability of a given city or neighborhood. Walk scores have been found to be a valid measure of the physical activity profile of a particular locality. However, there is a paucity of studies that have utilized walkability scores as a tool for determining the walkability of communities. This study aimed at assessing the accessibility of physical amenities in the upper east Texas counties by analyzing the walk scores for the various cities derived from www.walkscore.com, an online resource that promotes walking as a healthy lifestyle in urban communities. This study therefore relied on the walk score for selected cities to establish the walkability profile of the various cities in upper east Texas.

\section{Methods and materials}

This study involved collection of Walk Score data for the upper east Texas Counties (see Table 1). The 23-county upper east Texas region stretches from the piney woods bordering Arkansas and Louisiana to the eastern edge of the Dallas-Fort worth Metroplex (Combs, 2008). This data was accessed from www.walkscore.com in the fall of 2013. According to Duncan et al., (2011), Walk Score ${ }^{\circledR}$ (www.walkscore.com) is a publicly available large-scale method for calculating walkability. Walk Score was developed by Front Seat Management (www.frontseat.org), a software development company based in Seattle, WA, which focuses on software with civic applications. These authors further explain that Walk Score uses publicly available data to assign a score to a location based on the distance to and variety of nearby commercial and public frequently-visited facilities. Data sources used by Walk Score include Google, Education.com, Open Street Map and Localeze. Facilities are divided into five categories: educational (e.g., schools), retail (e.g., grocery, drug, convenience and bookstores), food (e.g., restaurants), recreational (e.g., parks and gyms) and entertainment (e.g., movie theaters).

The Walk Score algorithm then calculates the distance to the closest of each of the five facilities, using straight-line distances, and calculates a linear combination of these distances weighted both by facility type priority and a distance decay function (Duncan et al., 2011). The Walk Score data has previously been validated by Duncan et al., (2011), Carr et al., (2010) and Carr et al., (2011) as viable for establishing the physical activity profile of a community. The walk score helps one to find a walkable place to live depending on preference on accessing certain utilities including physical activity, grocery stores, super markets, restaurants, apartments etc. The Walk Score is a number between 0 and 100 that measures the walkability of any address.

The scoring between 90 and 100 is a walker's paradise where daily errands do not require a car; 70 to 89 , is very walkable as most errands can be accomplished on foot; 50 to 69 is somewhat walkable as some errands can be accomplished on foot; 25 to 49 is car dependent as most errands require a car and 0 to 24 is car dependent as almost all errands require using a car. 
Njororai Simiyu, W. W., Njororai, F. J., \& Jivetti, B. A (2016). Walkability in upper east Texas cities and implications for physical activity and health. International Journal of Human Sciences, 13(1), 487-499. doi:10.14687/ijhs.v13i1.3438

\section{Results}

Table 1 shows the 23 upper east Texas counties and their headquarters and the portion within the larger state of Texas. This Piney Wooded region of Texas has a number of cities and small towns located in several counties. The cities that form the seats of the various counties are listed in Table 1.

Table 1

Upper East Texas Counties and their Headquarters

\begin{tabular}{ll}
\hline County name & County seat \\
\hline Anderson & Palestine \\
Bowie & New Boston \\
Camp & Pittsburg \\
Cass & Linden \\
Cherokee & Rusk \\
Delta & Cooper \\
Franklin & Mt. Vernon \\
Gregg & Longview \\
Harrison & Marshall \\
Henderson & Athens \\
Hopkins & Sulphur Springs \\
Lamar & Paris \\
Marion & Jefferson \\
Morris & Daingerfield \\
Panola & Carthage \\
Rains & Emory \\
Red River & Clarksville \\
Rusk & Henderson \\
Smith & Tyler \\
Titus & Mt. Pleasant \\
Upshur & Gilmer \\
Van Zandt & Canton \\
\hline
\end{tabular}

The upper east Texas region has 22 Counties, most of which are rural than Texas as a whole as of 2007. Metropolitan counties accounted for just 46 percent of the region's population, whereas 87 percent of all Texas residents lived in metro areas in 2007 (Combs, 2008).

\section{Walkability Scores}

Various cities in upper east Texas region were found to exhibit a range of walkability scores (see Table 2). 
Njororai Simiyu, W. W., Njororai, F. J., \& Jivetti, B. A (2016). Walkability in upper east Texas cities and implications for physical activity and health. International Journal of Human Sciences, 13(1), 487-499. doi:10.14687/ijhs.v13i1.3438

Table 2

The Walkability Percentage Score of upper east Texas Cities

\begin{tabular}{|c|c|c|c|c|c|}
\hline City & $\begin{array}{l}\text { Walk } \\
\text { score } \%\end{array}$ & City & $\begin{array}{l}\text { Walk } \\
\text { score } \\
\%\end{array}$ & City & $\begin{array}{l}\text { Walk } \\
\text { score } \\
\%\end{array}$ \\
\hline 1. Joinerville & 0 & 21. New Boston & 31 & 41. Frankston & 51 \\
\hline 2. Starrville & 3 & 22. Overton & 31 & 42. Jacksonville & 55 \\
\hline 3. Flint & 8 & 23. Tyler & 32 & 43. Malakoff & 55 \\
\hline 4. New Chapel Hill & 8 & 24. Paris & 34 & 44. Gresham & 57 \\
\hline 5. New London & 8 & 25. Gun Barrel City & 37 & 45. Canton & 58 \\
\hline 6. Noonday & 8 & 26. Linden & 37 & 46. Quitman & 58 \\
\hline 7. Murchison & 11 & 27. Alto & 38 & 47. Mt. Pleasant & 60 \\
\hline 8. Winona & 11 & 28. Mt. Vernon & 38 & 48. Sulphur Springs & 62 \\
\hline 9. New Summerfield & 15 & 29. Troup & 38 & 49. Winnsboro & 65 \\
\hline 10. Brownsboro & 18 & 30. Grand Saline & 40 & 50. Jefferson & 68 \\
\hline 11. Arp & 23 & 31. Chandler & 42 & 51. Marshall & 68 \\
\hline 12. Edom & 23 & 32. Pittsburg & 45 & 52. Kilgore & 69 \\
\hline 13. Palestine & 23 & 33. Whitehouse & 45 & 53. Mineola & 72 \\
\hline 14. Lufkin & 26 & 34. Gilmer & 46 & 54. Atlanta & 74 \\
\hline 15. Texarkana & 26 & 35. Rusk & 46 & 55. Henderson & 74 \\
\hline 16. Uncertain & 26 & 36. Daingerfield & 48 & 56. Carthage & 82 \\
\hline 17. Longview & 28 & 37. Gladewater & 48 & 57. Athens & 91 \\
\hline 18. Van & 28 & 38. Lindale & 48 & & \\
\hline 19. Hawkins & 29 & 39. Bullard & 49 & & \\
\hline 20. Nacogdoches & 29 & 40. Clarksville & 51 & & \\
\hline
\end{tabular}

Legend:

1. 90 and 100 is a walker's paradise where daily errands do not require a car;

2. 70 to 89 , is very walkable as most errands can be accomplished on foot;

3. 50 to 69 is somewhat walkable as some errands can be accomplished on foot;

4. 25 to 49 is car dependent as most errands require a car; and

5. 0 to 24 is extremely car dependent as almost all errands require using a car.

The results revealed that $13(22.8 \%)$ cities, namely Joinerville, Starrville, Flint, New Chapel Hill, New London, Noonday, Murchison, Winona, New Summerfield, Brownsboro, Arp, Edom, and Palestine had walkable scores that fall in the 0 to 24 category which is car dependent as almost all errands require using a car. Twenty six (45.6\%) cities including Lufkin, Texarkana, Uncertain, Longview, Van, Hawkins, Nacogdoches, New Boston, Overton, Tyler, Paris, Gun Barrel City, Linden, Alto, Mt. Vernon, Troup, Grand Saline, Chandler, Pittsburg, Whitehouse, Gilmer, Rusk, Daingerfield, Gladewater, Lindale, and Bullard had scores within the 25 to 49 range that is car dependent as most errands require a car. The walkability percentage scores for cities in upper east Texas can be seen in figure 1. 
Njororai Simiyu, W. W., Njororai, F. J., \& Jivetti, B. A (2016). Walkability in upper east Texas cities and implications for physical activity and health. International Journal of Human Sciences, 13(1), 487-499. doi:10.14687/ijhs.v13i1.3438

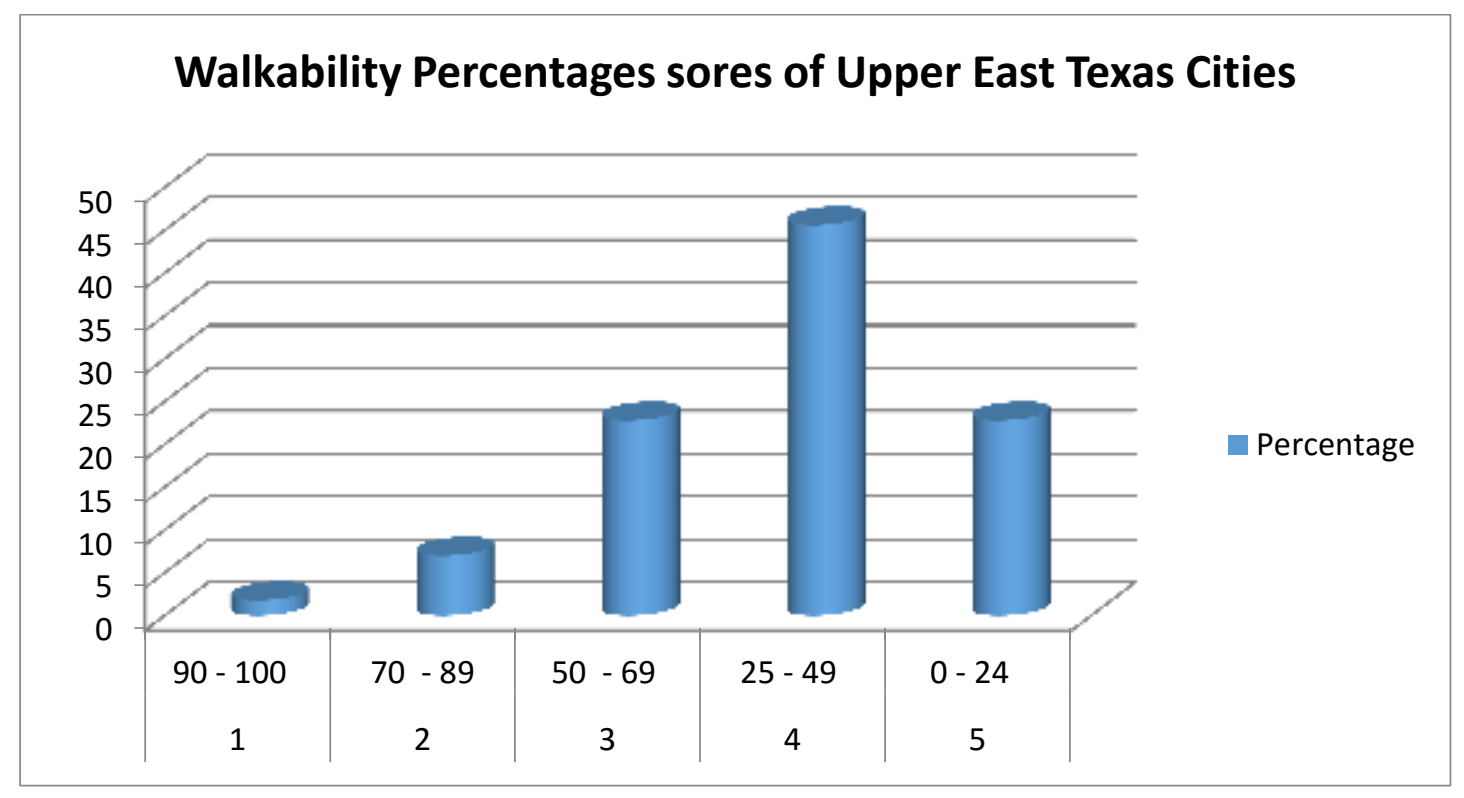

Figure 1. The Walkability Percentages of the 57 upper east Texas cities

Thirteen $(22.8 \%)$ of the cities including Clarksville, Frankston, Jacksonville, Malakoff, Gresham, Canton, Quitman, Mt. Pleasant, Sulphur Springs, Winnsboro, Jefferson, Marshall and Kilgore had scores within the 51 to 69 range that is somewhat walkable as some errands can be accomplished on foot. Four $(7 \%)$ cities, including Mineola, Atlanta, Henderson and Carthage had scores between 70 and 89, which is very walkable as most errands can be accomplished on foot. Only one city, Athens, had a walkable score of 91, which falls in the 90 to 100 range that is a walker's paradise where daily errands do not require a car.

These results show that the majority of cities in upper east Texas score below $69 \%$ on the Walkability score which reflect neighborhoods that are very car dependent. This is an indicator of the need to actively pursue an agenda that promotes infrastructural investments that can bring about ease of walking and accessibility of community services at close range.

\section{Discussion}

According to Bauman et al., (2012), walking is convenient, easy for most people to do, and requires no special equipment. These authors add that the built environment can influence how much people walk. Youth and adults who live in walkable neighborhoods are more likely to be physically active (Njororai, et al., 2015). It is also important to point out that walkable neighborhoods offer a variety of benefits to peoples' health, the environment, finances, and communities. Apparently, the way neighborhoods are designed with respect to proximity and connectivity to local destinations, including schools, parks and shopping centers, and the presence of footpaths - becomes a determinant of whether people are able to walk and use destinations locally (Foundation, 2011; Njororai, et al., 2015). A growing body of evidence shows that the built environment can positively influence physical activity for both recreational and transportation purposes (Foundation, 2011; Heath et al., 2006; Kahn et al., 2002). According to the social-ecological framework of behavior change, people's behaviors are influenced by many factors including family, friends, local surroundings, built environment, and community (Flora \& Flora, 2012; Rogers, 2013; Sinnett et al., (2011). Rogers (2013) contends that in order to bring 
Njororai Simiyu, W. W., Njororai, F. J., \& Jivetti, B. A (2016). Walkability in upper east Texas cities and implications for physical activity and health. International Journal of Human Sciences, 13(1), 487-499. doi:10.14687/ijhs.v13i1.3438

about behavior change, the supporting environments and policies must be changed to make it easier for people in those environments to make healthy choices. If people are to enjoy health and developmental benefits of independent mobility, a key priority must be in reducing exposure to traffic and in increasing surveillance on streets through neighborhood and building design, by encouraging others to walk locally, and by discouraging motor vehicle use in favor of walking and cycling. According to Rogers et al., (2010):

The ability to comfortably walk to locations of need and importance in one's home neighborhood and quality of life have been linked by researchers, practitioners, and home owners. The research ... suggests that there is another component of the equation linking walkability to quality of life and that is social capital. Analysis of a survey of neighborhoods of varying built form revealed strong correlations between the number of locations one could walk to and indicators of social capital. Just like economic and human capital, social capital can bring benefits to those who possess it, such as reduced isolation, career enhancement connections, neighborhood safety, to name a few. It is these benefits that may enhance an individual's quality of life. Walkability enhances social capital by providing the means and locations for individual to connect, share information, and interact with those that they might not otherwise meet (p. 213).

It is argued that the average resident of a walkable neighborhood weighs 6-10 pounds less than someone who lives in a sprawling neighborhood. Cities with good public transit and access to amenities promote happiness. Additionally environmental-wise, more walking reduces carbon dioxide emissions from burning fossil fuels as peoples' feet are zero-pollution transportation machines. Studies show that for every 10 minutes a person spends in a daily car commute, time spent in community activities falls by $10 \%$. The amenities that make a neighborhood walkable include a center, people to attract businesses and for public transit to run frequently; mixed income, mixed use: affordable housing located near businesses; parks and public space: plenty of public places to gather and play; pedestrian design: schools and workplaces are close enough that most residents can walk from their homes; and streets are designed for bicyclists, pedestrians, and transit (Sinnett et al., (2011).

Higher levels of out-of-school-hours physical activity and walking appear to be significantly associated with higher levels of urban density and neighborhoods with mixed-use planning, especially for older children and adolescents. Proximate recreational facilities also appear to predict young people's level of physical activity (Rogers et al., 2010; Sinnett et al., 2011). However, there are inconsistencies in the literature involving studies with younger children. Independent mobility increases with age. For younger children, the impact of the built environment is influenced by the decision-making of parents as the gatekeepers of their behavior. Cross-cultural differences may also be present and are worthy of greater exploration (Njororai, et al., 2015).

As children develop and are given more independent mobility, it appears that the way neighborhoods are designed - particularly in terms of proximity and connectivity to local destinations, including schools and shopping centers, and the presence of footpaths - becomes a determinant of whether children are able, and are permitted by their parents, to walk and use destinations locally (Sinnett et al., 2011). If older children and adolescents are to enjoy health and developmental benefits of independent mobility, a key priority must be in reducing exposure to traffic and in increasing surveillance on streets (i.e. 'eyes-on-the-street') through neighborhood and building design, by encouraging others to walk locally, and by discouraging motor vehicle use in favor of walking and cycling (Sinnett et al., 2011). Parents need to be assured that the rights and safety of pedestrians (and cyclists) - particularly child pedestrians and cyclists - are paramount 
Njororai Simiyu, W. W., Njororai, F. J., \& Jivetti, B. A (2016). Walkability in upper east Texas cities and implications for physical activity and health. International Journal of Human Sciences, 13(1), 487-499. doi:10.14687/ijhs.v13i1.3438

if we are to turn around our 'child-free streets', now so prevalent in contemporary Australian and U.S. cities (Njororai, et al., 2015; Sinnett et al., 2011).

\section{Implications for policy and practice}

Upper east Texas is a region that is dominated by an aging population, as well as an abundance of natural resources such as lakes, parks, and other recreational facilities. Increased population aging creates new challenges and demands to societies including the occurrence of more acute diseases. Some of these diseases and conditions are costly to treat and require a significant allocation of resources. Decreased smoking, better nutrition, stress reduction, and exercise are some examples of improvements in lifestyle that can contribute to healthy aging. Additional studies suggest that physical activities help maintain good mental function (Novak, 2012).

It is vital that principle stakeholders come together to determine reasons for the minimal walkability in the region so that practical intervention strategies are generated to enhance the well-being of the residents. There is also need for policy makers to review existing built capital with the aim of making investments that are efficient and sustainable (Rogers et al., 2010). This will have further meaningful implications on the use of natural and financial capital for the upper east Texas communities.

Researchers and their agencies need to share information and interpretations with other stakeholders such as planners, economic and community development officials, and neighborhood leaders in the cities so that they can help address community needs. While it is just a start, the data analyzed here shows a need to study the built environment and social capital within these cities in the region. This is vital as research (Flora \& Flora, 2012; Novak, 2012; Rogers, 2013; Rogers et al., 2010; Sinnett et al., 2011) shows the importance of social capital as a component in the link between walkability and quality of life. The community capitals framework echoes this connection in the capitals and how we can use the same to focus investments. Studies show that neighborhood walkability has broad implications for health, sustainability, and many other components of quality of life. Additionally, it has implications on perceptions on sense of belonging to a community.

Therefore, this calls for interventions at community, workplace and policy level to promote physical activity, especially walking, and not just medical and health practitioners. There is need for a network involving custodians at all levels to improve the efficiency of physical activity promotion throughout the social, economic and physical environment. The need for collaborative efforts to facilitate and promote physical activity is made more urgent given the escalating costs of health care. It is recommended that policy makers strive to provide for physical activity friendly environments to accommodate safe walking and biking if the physical activity profile of this upper east Texas locality is to improve.

Physical activity enthusiasts need to embrace walking as part of their regular exercise activity. Similarly, educational institutions need to design physical activity programs that are suitable for all age groups. A need also exists for health institutions to focus on these kinds of low-cost initiatives for preventing some of the health conditions associated with sedentary lifestyles that most citizens tend to exhibit. By so-doing, we could save a lot on health care costs and utilize the savings on other meaningful developments that confer fulfilled lives and longevity.

The key strategies that have been suggested in the literature and emphasized by Collins and Fulton (2015) to promote walking in the United States include: 
Njororai Simiyu, W. W., Njororai, F. J., \& Jivetti, B. A (2016). Walkability in upper east Texas cities and implications for physical activity and health. International Journal of Human Sciences, 13(1), 487-499. doi:10.14687/ijhs.v13i1.3438

1. Improving the physical environment to support walking, such as having safe streets with sidewalks and crosswalks or attractive areas to walk, including nearby trails or parks.

2. Personal motivation for walking which may include walking the dog or walking to nearby destinations, such as public transit, stores, or schools.

3. Other motivating factors can include social support, such as when friends or family walk together on a regular basis or when they use a step counter and a daily step goal. Indeed, combining these supports may substantially increase walking, especially where social media support, pedometer use, and a steps goal used in combination increased walking in young women approximately 1.5 miles per day over a standard walking intervention.

4. Partnering with sectors beyond traditional public health and physical activity domains to include transportation, land use, and community design sectors. This is vital as working with community planners and transportation engineers can ensure that new or renovated streets improve access for all users regardless of whether they drive, walk, or bike. This collaboration among different experts can design environments that are physical activity friendly and, therefore, help promote physical activity participation.

5. Public transportation has been shown to increase walking as it is best utilized in places with the greatest need and population density.

6. Finally, mixed land-use designs that include housing, transportation, and other destinations, such as stores and restaurants that are in close proximity to one another, are environments that promote walking. Improving health may not be on the minds of urban planners, although walkable communities are highly desirable destinations for housing, shopping, employment, and leisure-time pursuits.

\section{References}

Adger, W. N. (2003). Social capital, collective action and adaptation to climate change, Economic Geography, 79(4).

Bauman, A. E., Reis, R. S., Sallis, J. F., Wells, J. C., Loos, R. J. F., Martin, B. W. (2012). Correlates of physical activity: Why are some people physically active and others not? Lancet, 380 (9838): 258-271.

Blackwell, D. L., Lucas, J. W. and Clarke, T. C. (2014). Summary health statistics for U.S. adults: National Health Interview Survey, 2012. Vital Health Stat, 10, 260.

Carr, L. J., Dunsiger, S. I., and Marcus, B.H. (2010). Walk score as a global estimate of neighborhood walkability. Am. J. Prev. Med., 39, 460-463.

Carr, L. J., Dunsiger, S.I. and Marcus, B.H. (2011). Validation of Walk Score for estimating access to walkable amenities. Br. J. Sports Med., 45, 1144-1148.

Collins, J. L. and Fulton, J. E. (2015). Taking Steps to a Healthier Nation: Increasing Physical Activity through Walking. Journal of Physical Activity and Health, 12 (Suppl 1), S1-S2. Combs, S. (2008). Texas in Focus: Upper East Texas. Texas Controller of Public Accounts Report.

Duncan, D. T., Aldstadt, J., Whalen, J., Melly, S. J. and Gortmaker, S. L. (2011). Validation of Walk Score ${ }^{\circledR}$ for Estimating Neighborhood Walkability: An Analysis of Four US Metropolitan Areas. Int. J. Environ. Res. Public Health, 8, 4160-4179; doi: 10.3390/ijerph8114160-4199.

Ferreira, I., van der Horst, K., Wendel-Vos, W., Kremers, S., van Lenthe, F. J., and Brug, J. (2006). Environmental correlates of physical activity in youth - a review and update. Obesity reviews, 8:129-154.

Flora, C. B., and Flora, J. L. (2012). Rural Communities: Legacy and Change. $4^{\text {th }}$ Edition. Boulder, CO: Westview Press. 
Njororai Simiyu, W. W., Njororai, F. J., \& Jivetti, B. A (2016). Walkability in upper east Texas cities and implications for physical activity and health. International Journal of Human Sciences, 13(1), 487-499. doi:10.14687/ijhs.v13i1.3438

Foundation, Robert Wood Johnson (January, 2011). Active Living Research: The Power of Trails for Promoting Physical Activity in Communities. Research Brief. Retrieved from www.activelivingresearch.org.

Frank LD, Sallis JF, Saelens BE, Leary L, Cain K, Conway T, Hess P. (2009). The development of a walkability index: application to the Neighborhood Quality of Life Study. BrJ Sports Med doi:10.1136/bjsm.2009.058701 [Online 29 April 2009].

Halstead, J.M. and S.C. Deller. (1997). Public Infrastructure in Economic Development and Growth: Evidence from Rural Manufacturers. Journal of Community Development Society, 28:149-69.

Heath, G. W., Brownson, R. C., Kruger, J., et al. (2006). The effectiveness of urban design and land use and transport policies and practices to increase physical activity: a systematic review. J Phys Act Health, 3(Suppl 1):S55-S76.

Jarema, P., Halstead, J., \& Conway, K. (2009). Civic Engagement and Land Use Policy Change: Does Social Capital Affect Ecosystem Service Flows? Paper Presentation Northeast Agriculture and Resource Economics Annual Conference, Burlington, VT, June 7-9.

Johnson, R. K. (2000). Changing eating and physical activity patterns of US children. Proc NutrSoc, 59: 295-301.

Kann, L., Kinchen, S., Shanklin, S. L. et al., (2014). Centers for Disease Control and Prevention. Youth risk behavior surveillance- United States 2013. MMWR Surveill Summ, 63 (suppl 4); 1-168.

Kegler, M. C., Alcantara, I., Haardorfer, R., Gemma, A., Ballard, D., and Gazmararian, J. (2015). Rural Neighborhood Walkability: Implications for Assessment. Journal of Physical Activity and Health, 12 (Suppl 1), S40-S45.

Leyden, K. M. (2003). Social Capital and the Built Environment: The Importance of Walkable Neighborhoods. American Journal of Public Health, 93 (9), 1546 - 1551.

Lund, H. (2003). Testing the Claims of New Urbanism: Local Access, Pedestrian Travel and Neighboring Behaviors. Journal of the American Planning Association, 69:414-29.

McCrea, R., Shyy, T., \& Stimson, R. (2006). What is the strength of the link between objective and subjective indicators of urban quality of life? Applied Research in Quality of Life, 1, 79_ 96.

Njororai Simiyu, W. W., Njororai, F., and Jivetti, B. A. (2015). Walkable scores for selected three east Texas counties: physical activity and policy implications. International Journal of Human Sciences, 12 (2), 674-687.

Novak, M. (2012). Issues in aging. 3rd ed. Boston: Pearson.

Ogden, C. L., Carroll, M. D., Kit, B. K., and Flegal, K. M. (2012). Prevalence of obesity in the United States, 2009-2010. NCHS data brief, no 82. Hyattsville, MD: National Center for Health Statistics.

Ogden, C. L., Carroll, M. D., Fryar, C. D., and Flegal, K. M. (2015). Prevalence of obesity among adults and youth: United States, 2011-2014. NCHS data brief, no.219. Hyattsville, MD: National Center for Health Statistics.

Putnam, R. D. (2000). Bowling alone. New York: Simon \& Schuster.

Rogers, T. (2013). Sharing the News: 2012 Annual report. Let's Go!

Rogers, S. H., Halstead, J. M., Gardner, K. H., and Carlson, C. H. (2010). Examining Walkability and Social Capital as Indicators of Quality of Life at the Municipal and Neighborhood Scales. Applied Research in Quality of Life, 6 (2), 201-213. 
Njororai Simiyu, W. W., Njororai, F. J., \& Jivetti, B. A (2016). Walkability in upper east Texas cities and implications for physical activity and health. International Journal of Human Sciences, 13(1), 487-499. doi:10.14687/ijhs.v13i1.3438

Sinnett, D., Williams, K., Chatterjee, K. and Cavill, N. (2011). Making the case for investment in the walking environment: A review of the evidence. Technical Report. Living Streets, London.

Sirgy, J. M., Michalos, A. C.,Ferriss, A. L., Easterlin, R.,A., Patrick, D. and Pavot, W. (2006). The Quality-of-Life (QOL) Research Movement: Past, Present, and Future. Social Indicators Research, 76:343-466.

Song, M. K., Carroll, D. D., Lee, S. M., Fulton, J. E. (2015). Physical activities of U.S. high school students-2010 National Youth Physical Activity and Nutrition Survey. J Phys Act Health, 12(Suppl 1):S11-S17.

Valls, M. G. (September, 2012). Overweight and Obesity: Texas State Nutrition, Physical Activity, and Obesity Profile. CDC National Center for Chronic Disease Prevention and Health Promotion, Division of Nutrition, Physical Activity and Obesity. Retrieved from http://www.cdc.gov/obesity/stateprograms/fundedstates/pdf/texas-state-profile.pdf

Watson, K. B., Frederick, G. M., Harris, C. D., Carlson, S. A., Fulton, J. E. (2015). U.S. adults' participation in specific activities: Behavioral Risk Factor Surveillance System-2011. J Phys Act Health, 12 (Suppl 1):S3-S10.

World Health Organization (1998). Obesity: Preventing and Managing the Global Epidemic. Geneva: Report of a World Health Organization Consultation on Obesity.

World Health Organization (2000a). Health Behaviour in School-Aged Children: A WHO CrossNational Study (HBSC). Geneva: International Report World Health Organization Regional Office for Europe.

World Health Organization (2000b). Obesity: preventing and managing the global epidemic. Report of a WHO consultation. Geneva, Switzerland: World Health Organization. WHO Technical Report Series 894.

World Health Organization (2004). Global Strategy on Diet, Physical Activity and Health. Geneva: WHO. 